\title{
ANTROPOLOGIA CRÍTICA E CARTOGRAFIAS DO PODER SOBERANO NAS FRONTEIRAS DO CONE SUL
}

\author{
ALEX MARTINS MORAES ${ }^{1}$
}

\begin{abstract}
RESUMO
Esta intervenção se propõe a fundamentar e a exemplificar uma estratégia de análise antropológica orientada à crítica imanente das realidades do poder. Com este objetivo, recupero um relato construído durante pesquisa de campo realizada nas adjacências da divisa política entre Brasil e Uruguai. Tal relato evidencia os itinerários de deslocamento transfronteiriço empreendidos por uma família de classe popular instalada na cidade de Aceguá, limítrofe com o povoado uruguaio homônimo. A situação migratória irregular dos integrantes desta família deu origem a processos de exclusão que revelam os paradoxos inerentes à operatória da razão de Estado em zonas fronteiriças. Abordo os itinerários dos meus interlocutores como uma espécie de cartografia crítica que evidencia as exclusões e as possibilidades imanentes à articulação entre experiência de classe e poder soberano nas fronteiras do Cone Sul.
\end{abstract}

\section{PALAVRAS-CHAVE}

Antropologia crítica; Imanência; Estado; Fronteiras; Cone Sul

\section{CRITICAL ANTHROPOLOGYAND CARTOGRAPHIES OF SOVEREIGN POWER AT SOUTHERN CONE BORDERS}

\begin{abstract}
This paper intends to settle the foundations and reveal the strategies of anthropological analysis based on the immanent critic to power configurations. In order to do so, I resort to some narratives collected during a field research carried out in the outskirts of the national border zone of Uruguay and Brazil. Such narratives depict the trajectories of displacement across the national borders as experienced by one working-class family that is settled in the Brazilian city of Aceguá, adjacent to the homonymous Argentine village. The irregular migratory status of the members of this family resulted in social exclusion processes that reveal the contradictions inherent to the modus operandi of the State reason in border zones. I understand my interviwees itineraries as a sort of critical cartography that reveals the forms of exclusion and the immanent possibilities originated in the articulation between these people's class experience and the sovereign power at national border zones in the Southern Cone region.
\end{abstract}

\section{KEYWORDS:}

Critical anthropology; Immanence; State; Borders; Southern Cone

\footnotetext{
${ }^{1}$ Bolsista de doutorado do Consejo Nacional de Investigaciones Científicas y Técnicas (CONICET) vinculado ao Centro de Investigaciones Sociales do Instituto de Desarrollo Económico y Social (CISIDES). Membro do Instituto de Experimentação e Pesquisa Social-Outras Margens e do Grupo de Estudos em Antropologia Crítica.
} 


\title{
ANTHROPOLOGIE CRITIQUE ET CARTOGRAPHIES DU POUVOIR SOUVERAIN SUR LES FRONTIËRES DU CONNE SUD
}

\begin{abstract}
RÉSUMÉ
Cette intervention vise à soutenir théoriquement et illustrer ethnographiquement une stratégie d'analyse anthropologique destiné à la critique immanente des réalités du pouvoir. Compte tenu de cet objectif, je récupère quelques récits élaborées au cours de mon travail sur le terrain dans la frontière politique entre le Brésil et l'Uruguay. Ces récits montrent les itinéraires de circulation transfrontalière menées par une famille de classe populaire installée dans la ville brésilienne de Aceguá, à côté de la ville uruguayenne éponyme. Le statut migratoire irrégulière des membres de cette famille a déclenché des processus d'exclusion qui révèlent les paradoxes inhérents à la raison d'État dans les zones frontalières. J'analyse les itinéraires de mes interlocuteurs comme une sorte de cartographie critique qui met en évidence les exclusions et les possibilités immanentes à la l'articulation entre l'expérience de classe et le pouvoir souverain sur les frontières du Cône Sud.
\end{abstract}

\section{MOTS-CLÉS}

Anthropologie critique; Immanence; État; Frontières; Cône Sud

\section{ANTROPOLOGÍA CRIITICA Y CARTOGRAFÍAS DEL PODER SOBERANO EN LAS FRONTERAS DEL CONO SUR}

\begin{abstract}
RESUMEN
Esta intervención se propone fundamentar y ejemplificar una estrategia de análisis antropológico basada en la crítica inmanente de las realidades del poder. Con este objetivo, recupero un relato elaborado durante mi trabajo de campo en las adyacencias del límite político entre Brasil y Uruguay. Dicho relato evidencia los itinerarios de desplazamiento transfronterizo emprendidos por una familia de clase popular instalada en la ciudad de Aceguá, limítrofe con el poblado uruguayo homónimo. La situación migratoria irregular de los integrantes de esta familia desencadenó procesos de exclusión que revelan las paradojas inherentes a la operatoria de la razón de Estado en zonas fronterizas. Abordo los itinerarios de mis interlocutores como una especie de cartografía crítica que pone de relieve las exclusiones y posibilidades inmanentes a la articulación entre experiencia de clase y poder soberano en las fronteras del Cono Sur.
\end{abstract}

\section{PALABRAS CLAVE}

Antropología crítica; Inmanencia; Estado; Fronteras; Cono Sur 


\section{INTRODUÇÃO ${ }^{2}$}

A mobilidade territorial e as práticas binacionais estão presentes na vida da maioria dos moradores da fronteira brasileiro-uruguaia. Elas podem ser agenciadas nos mais diversos contextos, que incluem transações comerciais cotidianas, aquisições fundiárias a preços vantajosos, busca por postos de trabalho disponíveis no país vizinho, mudança de domicílio motivada por flutuações no valor dos alugueis, uso de serviços públicos, recomposições familiares, etc. Esta mobilidade mais ou menos contingente é favorecida pela contiguidade territorial entre as localidades fronteiriças e propicia uma fluida negociação dos diacríticos atribuídos às nacionalidades brasileira e uruguaia. Contudo, se a nacionalidade dos sujeitos não determina per se as clivagens e hierarquizações vigentes na fronteira, isto não quer dizer que a vida binacional transcorra numa atmosfera de irmandade alheia a processos radicais diferenciação. Dediquei-me especificamente a análise destes processos numa pesquisa desenvolvida entre os anos de 2010 e 2012 nas adjacências da fronteira política entre Brasil e Uruguai (MORAES, 2013). O estudo em questão me permitiu constatar que se bem os trânsitos e intercâmbios transfronteiriços são estimulados pela regionalização econômica do Cone Sul e pela facilidade de cruzamento da fronteira seca, eles também precisam responder às condicionantes de uma geopolítica mais rígida, balizada pelo poder soberano dos estados nacionais. Este poder institucional de arbítrio, que permite determinar quem pertence e quem não pertence à dada jurisdição territorial - e, por conseguinte, quem acessa e quem deixa de acessar determinados recursos -, organiza e condiciona diversas experiências sociais na fronteira brasileiro-uruguaia. Sua materialização ocorre, frequentemente, no âmbito das interações entre sujeitos e instituições públicas, sempre e quando o acesso aos benefícios e serviços outorgados por estas últimas encontra-se condicionado ao requerimento de documentos nacionais de identificação ou à comprovação de regularidade da situação migratória. É no contato com as instituições públicas que a lógica escrutinadora e dualista do poder soberano está em condições de operar sobre a vida pessoas, conduzindo, eventualmente, à negação de direitos, à reiteração das subordinações sociais vigentes e, no limite, à precarização da vida.

Ainda que a sociedade fronteiriça esteja atravessada por práticas binacionais de diversa ordem, são os deslocamentos empreendidos por famílias empobrecidas de trabalhadores informais que costumam originar situações de indocumentação prolongada e de segregação institucional. Isto ocorre por duas razões fundamentais. Em primeiro lugar

\footnotetext{
${ }^{2}$ As intuições teóricas que orientam esta intervenção são fruto, em boa medida, de minha participação nos debates promovidos pelo Grupo de Estudos em Antropologia Crítica (GEAC), do qual participo há cinco anos. Agradeço aos pareceristas anônimos da revista Mundaú por suas valiosas sugestões para o aperfeiçoamento da proposta metodológica aqui desenvolvida. Todas as conclusões e opiniões apresentadas neste texto são, claro, de minha exclusiva responsabilidade.
} 
porque, historicamente, o corredor fronteiriço compartilhado por Brasil e Uruguai comporta um mercado de trabalho internacionalizado no qual o desempenho de atividades laborais exige que os sujeitos estejam dispostos a franquear os limites entre estados-nacionais em condições migratórias irregulares. Em segundo lugar, porque os meios institucionais para obter documentos nacionais supõem consideráveis gastos financeiros e nem sempre se encontram disponíveis nas pequenas cidades e povoados limítrofes, permanecendo, portanto, inacessíveis aos grupos em maior desvantagem econômica (MORAES, 2014). Nesta intervenção, recupero os itinerários de uma família binacional que precisou enfrentar clivagens desta natureza, com todos os efeitos de exclusão delas resultantes. Retomar este registro etnográfico me ajudará a demonstrar as potencialidades de um procedimento crítico orientado à enunciação das possibilidades transformadoras imanentes às determinações instauradas pelo poder soberano.

A ênfase do argumento desenvolvido ao longo do artigo não recai exatamente sobre o conteúdo descritivo resultante do trabalho de campo na fronteira brasileiro-uruguaia, mas sim sobre o método que me permitiu plasmar, graças à pesquisa empírica, enunciados de tipo prescritivo, ou seja, formulações a respeito de como as coisas poderiam ser diferentes do que são tendo em vista uma conjuntura determinada. As antropologias latino-americanas de modo geral, e as brasileiras em particular, deram margem, pelo menos desde a década de sessenta do século passado, a uma constante preocupação teórico-política em torno da relação entre prática investigativa e tomada de posição do pesquisador no seio das realidades estudadas ${ }^{3}$. A presente intervenção faz eco desta preocupação e deseja não apenas reiterá-la, mas também fortalecê-la epistemologicamente com a convicção de que a antropologia crítica pode jogar um papel estratégico na definição do objeto e das razões disponíveis à projeção de novas políticas emancipatórias.

No primeiro tópico do artigo, exponho os fundamentos teórico-metodológicos de uma "crítica imanente" à operatória dos regimes de poder. A exposição do método está informada pelas intuições de György Lukács a respeito do "instante presente" enquanto momento privilegiado do pensamento transformador e pelo cativante chamado de Sylvain Lazarus em favor de uma antropologia orientada à "prescrição de possíveis". A delimitação da especificidade destas propostas teóricas se dá em contraste com uma das expressões atualmente mais visíveis da chamada "antropologia pública", aquela reivindicada por Didier Fassin. O efeito contrastivo visa realçar a singularidade de um procedimento crítico interessado em questionar as configurações atuais de poder sem precisar definir critérios ou

\footnotetext{
3 Myriam Jimeno (2004) revisa os principais debates da antropologia latino-americana, procurando indicar de que forma, ao longo do tempo, sua "vocação crítica" veio se atualizando. Em sua tese de doutorado, Mariza Peirano (1981) analisa a conformação do campo antropológico brasileiro e avalia como certos projetos políticos repercutiram nas ênfases investigativas desenvolvidas sob seu espectro.
} 
alternativas exteriores às situações de interlocução nas quais se referencia. O debate com Fassin também possui valor estratégico do ponto de vista da política da teoria. Sabemos que a obra do autor tem servido, nos últimos anos, de referência quase iniludivel para quem deseja estabelecer sinergia entre pesquisa antropológica e participação ativa nos debates públicos contemporâneos. Interpelar seu método, portanto, é uma forma de reconhecer a importância dos desafios aos quais ele tenta responder e, ao mesmo tempo, visibilizar outras possibilidades para enfrentá-los.

O segundo tópico, que dá início à demonstração do método, está dedicado ao caso de Jorge, Susana e seus três filhos. À época de minha pesquisa de campo, esta família composta por pais uruguaios e filhos nascidos no Brasil residia na cidade brasileira de Aceguá, um pequeno núcleo urbano limítrofe com o povoado uruguaio homônimo. No transcurso do relato, evidencio os procedimentos básicos de invisibilização que tornam o poder territorial do Estado brasileiro alheio às demandas dos sujeitos que habitam sua jurisdição, expondo-os a situações de abandono dificilmente negociáveis nos termos da razão estatal. De forma simultânea à descrição destes efeitos de poder, procuro revelar uma série de movimentos táticos que Jorge e Susana levaram a cabo para tentar acessar - desta vez no lado uruguaio da fronteira e em meio a novos infortúnios - os benefícios sociais dos quais se julgavam merecedores. Atento às avaliações oferecidas por meus interlocutores sobre o sentido de suas próprias ações, sintetizo alguns enunciados prescritivos que, de acordo com o método desenvolvido neste artigo, podem ser encarados como condições reais de impossibilidade da ordem atual. Em diálogo com os parâmetros metodológicos discutidos no primeiro tópico e tendo em vista o caso analisado na segunda parte do texto, dedico minhas palavras finais à indagação das relações entre enunciado prescritivo, antropologia crítica e ação política.

\section{A PROPÓSITO DO SENTIDO E DAS CONDIÇÕES DA CRÍTICA}

Entre os antropólogos públicos mais visíveis do momento, talvez Didier Fassin seja aquele que vem se esforçando por formular com maior sistematicidade as condições de possibilidade da reflexão crítica levando em conta as especificidades metodológicas da antropologia. Numa entrevista relativamente recente à Revista $\tilde{N}$, Fassin (2014) afirmava que a associação entre o método etnográfico - calcado no longo tempo de convívio com as pessoas estudadas - e uma forma propriamente antropológica de "aproximação" à realidade - que implica o exercício da generalização a partir de casos singulares - nos permite pensar o mundo de forma "crítica". Para definir sua própria posição a respeito do tipo de pensamento crítico que poderia emergir da prática investigativa em antropologia, Fassin (2009; 2011a) parte de uma tipologia estabelecida por Michael Walzer (1996). Este último recorre à 
alegoria platônica da caverna para diferenciar duas modalidades de se relacionar criticamente com o objeto de pesquisa em ciências sociais. A primeira consistiria em se posicionar fora da célebre caverna e, a partir dali, à luz do sol, procurar dissipar as ilusões nutridas pelos homens e mulheres que habitam a escuridão, indicando-lhes o caminho da verdade. Esta atitude corresponderia tipicamente ao "legado marxista" (FASSIN, 2011, p.484). A segunda abordagem, mais recente e enraizada na teoria pragmática, consistiria em partilhar da mesma condição dos habitantes da caverna, declinando da ideia de uma verdade exterior e aceitando que "o significado social é co-produzido pelos agentes sociais" (Idem) 4 . Fassin declina da necessidade de escolher entre luz ou escuridão e prefere instalar-se no "limiar da caverna", "numa posição a partir da qual é possível entrar e sair alternadamente" (FASSIN, 2011, p.485). Posicionado neste limiar, o antropólogo condicionaria sua capacidade de enunciação crítica à pergunta sobre o que se ganha e o que se perde na medida em que as conjunturas se transformam e novos critérios ético-morais passam a dinamizar a ação social e a vida coletiva.

Como delinear uma perspectiva analítica que permita pensar em termos de perdas e ganhos? Levando em conta as dinâmicas das quais se ocupa em suas pesquisas, Fassin sugere que o primeiro passo nesse sentido consiste em não tomar por dados os valores ético-morais que "constituem historicamente nosso senso comum" (FASSIN, 2012, p.19). Se as coordenadas que orientam nossa ação no mundo possuem historicidade, então é possível, argumenta o autor, começar a pensar a partir do pressuposto de que elas poderiam ter sido diferentes do que são. É nestas circunstâncias que a ponderação sobre perdas e ganhos adquire relevância crítica. Contudo, para levá-la a bom termo é necessário estabelecer marcos analíticos muito amplos que, por transcenderem a realidade imediata dos interlocutores, poderiam ser vistos como uma espécie de exterioridade da caverna. Graças à definição de marcos de referência abrangentes, geralmente ancorados numa genealogização das categorias sociais atualmente em uso, as situações tornam-se inteligíveis em sua singularidade e mutabilidade históricas.

Uma das expressões emblemáticas do procedimento crítico proposto por Fassin é sua problematização das políticas europeias de acolhida aos imigrantes e refugiados (ver, por exemplo, FASSIN, 2001; 2003; FASSIN; D'HALLUIN, 2005). Fassin constata que a partir de meados da década de setenta a relação dos estados-nação europeus com as populações imigrantes oriundas do Terceiro Mundo foram se redefinindo dramaticamente, a reboque da redução da demanda de mão-de-obra estrangeira nas indústrias locais. Rechaçada pela economia política, a presença imigrante se converteu numa questão de economia moral. Nas três últimas décadas, a verificação da utilidade laboral dos imigrantes deixou,

\footnotetext{
${ }^{4}$ Todas as citações de textos originais publicados em inglês e francês foram traduzidas ao português pelo autor.
} 
paulatinamente, de condicionar sua permanência em países como a França, cedendo lugar a discursos e tecnologias institucionais preocupados em perscrutar o sofrimento do qual seus corpos são capazes de dar testemunho para se tornarem caudatários de uma acolhida territorial pautada pela lógica da proteção humanitária. Na transição de um regime de governamentalidade codificado pela economia política em direção a outro informado pelos protocolos da compaixão, a capacidade de auto-enunciação dos sujeitos se redefiniu completamente. Seus corpos doentes ou eventualmente ameaçados pela perseguição política nos países de origem tornaram-se, pouco a pouco, a fonte básica de uma legitimidade social enunciada em termos de vitimização pelas autoridades estatais.

Efeitos de poder análogos aos mencionados anteriormente também se multiplicam na esteira das intervenções promovidas por organizações humanitárias internacionais como Médicos do Mundo ou Médicos sem Fronteira, da qual Fassin já foi vice-presidente. Em seus esforços por definir o objeto da assistência humanitária, os membros destas organizações reconfiguram sua própria percepção dos conflitos contemporâneos e dos sujeitos neles implicados. Quando, por exemplo, os dirigentes de Médicos do Mundo adotam a consigna de que "não existem vítimas boas ou vítimas más", no intento de justificar sua atividade nos dois lados do campo de batalha que opõe palestinos e isrealenses, eles acabam estabelecendo, segundo Fassin, "uma equivalência de vítimas com base na equivalência de seu sofrimento, abolindo, assim, qualquer distinção política possível" (FASSIN, 2011a, p.488). Isto naturalmente gera dilemas práticos para os profissionais envolvidos com a assistência humanitária posto que, concretamente, eles não conseguem "sustentar até seu limite máximo a equivalência entre as vítimas reivindicada pelo [gesto] humanitário" (FASSIN, 2009, p.205).

Defrontado com as práticas institucionais inspiradas pelo humanitarismo, Fassin argumenta que seu esforço crítico consiste, por um lado, em atentar para a forma como os interlocutores justificam certas ações intervencionistas em meio aos debates e contradições próprios de seu campo de ação e, por outro lado, em rastrear os pontos cegos das condutas analisadas, bem como os efeitos inesperados delas decorrentes. "Esta crítica - afirma Fassin se apóia, claro, sobre o que fazem, dizem e pensam os atores (...), mas [também] vai lá onde seria difícil para eles irem" (Idem). Este "lá" evocado pelo autor seria o plano da generalização. Informada pela análise de múltiplas dinâmicas localizadas, a generalização permite que o antropólogo vislumbre, por exemplo, o surgimento de um novo paradigma de governo humanitário das populações no ocaso das estruturas estatais que outrora tentaram mitigar, sem sucesso, as tragédias da modernidade (FASSIN, 2011b).

Deslocando-se entre o mundo mais imediato dos interlocutores e os insights proporcionados por um tipo generalização inspirado no método genealógico de Foucault, Fassin consegue dialogar criticamente com certas expressões do projeto humanitário ao 
passo que não se exime de problematizá-las em termos radicais e abstratos. Parafraseando Foucault, o autor define sua postura como uma aposta por "relançar tão longe e tão amplamente quanto seja possível o trabalho indefinido da liberdade" (FOUCAULT, 2001 apud FASSIN, 2009, p.206). Fazê-lo exige "escapar da alternativa entre dentro e fora: é necessário estar nas fronteiras" (Idem). O desafio mais elevado da crítica consistiria, então, em tensionar no plano do pensamento a onipotência da realidade atual, demonstrando sua verdadeira contingência e a particularidade historicamente definida dos efeitos de poder que a caracterizam. Ainda que Fassin não o diga explicitamente, parece-me razoável intuir que, das portas da caverna para fora, o antropólogo deve ser implacável no diagnóstico das aporias intrínsecas às lógicas contemporâneas de governo das populações, ao passo que das portas para dentro sua missão consistiria em compartilhar com os demais um relato sobre as perdas e ganhos derivados da transição entre diferentes regimes de governamentalidade. Esta segunda postura enriqueceria a consciência dos sujeitos a respeito das consequências e possibilidades contidas em suas ações. Como aponta um de seus comentadores, Fassin alterna, efetivamente, "entre uma crítica interna, simpática ao projeto humanitário, e uma [crítica] externa, majoritariamente informada pelas acusações de despolitização" (GUILHOT, 2012, p. 99).

O modelo elaborado por Didier Fassin está muito bem fundamentado e vem sendo aperfeiçoado ao longo dos anos em meio ao debate com seus críticos e entusiastas. Minha intenção, aqui, não é colocá-lo em questão nem discuti-lo em profundidade, até porque isto iria além do escopo do presente artigo. Quero apenas sugerir que mais além dos interiores, limiares e perímetros da caverna platônica existe outro lugar para fundamentar o enunciado antropológico crítico. Não se trata de desmerecer a proposta de Fassin, mas sim de apresentar, sucintamente, outra estratégia de enunciação crítica que nos permita, através da pesquisa de campo, não apenas dizer que as coisas poderiam ter sido diferentes do que são, mas também que elas podem, objetivamente, ser transformadas aqui e agora de acordo com critérios precisos.

Como vimos, o modelo de crítica proposto por Fassin consiste em nos dar uma ideia do que fomos e estamos deixando ser, de modo que possamos ver em perspectiva a série de mutações que desembocam em novas formas de exercício do poder. Definida a particularidade destas novas formas, o pesquisador procederá a identificar seus dilemas e aporias - lembremos do caso de Médicos do Mundo -, sempre disposto a reconhecer que eles não necessariamente "admitem solução tendo em vista o estado do mundo contemporâneo" (FASSIN, 2009, p.205). O desdobramento crítico da teoria adotada por Fassin compreende a afirmação de que mais além de soluções pontuais para dilemas igualmente pontuais existem questões de fundo ainda não resolvidas; questões cuja confrontação exige o questionamento radical das coordenadas que orientam a produção da 
realidade atual. Pois bem, neste ponto surgem as duas interrogações que me motivam a sair em busca de outras coordenadas para a produção do enunciado antropológico crítico.

Em primeiro lugar: é possível desenvolver a crítica empiricamente informada sem ficar necessariamente restrito ao olhar retrospectivo que constata que as coisas nem sempre foram como são, ou ao olhar prospectivo que afirma sozinho e a partir de sua autonomia intelectual uma liberdade indefinida? Em segundo lugar, existe a possibilidade de empreender uma crítica do mundo tal como ele é prescindindo de ponderações generalizantes sobre perdas e ganhos e utilizando apenas critérios que sejam imanentes a este mundo? A resposta para ambas as questões só pode ser afirmativa sob condição de substituirmos a alegoria da caverna pela noção de um real compartilhado que, por sua vez, não "é", salvo como conjunção de prescrições antagônicas. Antes proceder às necessárias especificações conceituais, quero fazer uma observação: a abordagem crítica pela qual advogo - e cujos fundamentos teóricos não poderei mais do que esboçar, dada a brevidade deste artigo - é caudatária de certo "legado marxista". Talvez Fassin se surpreendesse ao saber que György Lukács, conhecido filósofo marxista húngaro, havia decidido, há quase cem anos, situar a atividade crítica bem longe da alegoria da caverna - com seus respectivos umbrais e interiores - e bem próxima do "instante presente". Nas palavras de Lukács, é neste instante que "o pensamento se dissolve em processo [e é] momento de mediação profunda e ramificada, momento da decisão, momento de nascimento do novo" (LUKÁCS, 2013 [1922], p. 339) 5. No instante presente nada "é", tudo está vindo a ser. Existem, claro, formas, categorias e conceitos definidos; existe, em suma, "ordem". Contudo, também existem possíveis objetivos na medida em que há subjetividade e pensamento. Sem dialogar diretamente com Lukács, o antropólogo Sylvain Lazarus - que reivindica precedentes intelectuais como o de Lênin, bastante inusuais, diga-se de passagem, na antropologia mainstream - desenvolve intuições semelhantes às do filósofo húngaro e dedica toda uma obra (LAZARUS, 1996) à sua fundamentação teórica e ao estabelecimento dos requisitos para colocá-las à prova através da pesquisa social.

Lazarus nos convida a pensar o contemporâneo a partir das "singularidades". Estas, por sua vez, não são outra coisa senão a intelectualidade das pessoas. A singularidade não é a ruptura de um suposto Uno original, "não designa a passagem de uma problemática da totalidade, do Uno, em direção a uma problemática fenomenológica do múltiplo" (LAZARUS, 1996, p.48). Não há um mundo (Uno) lá fora porque não existe "dentro", mas apenas relações singulares do real não objetal. Em outras palavras, a intelectualidade das pessoas não é derivação ou reflexo de "algo" já estabelecido por outra intelectualidade, mas ramificação de um real que irrompe no pensamento e se transforma sob seu influxo. Daí que

\footnotetext{
${ }^{5}$ Para uma atualização destas intuições na obra tardia do autor, ver, por exemplo, Lukács (2012 [1984]).
} 
Lazarus goste de dizer que "o pensamento é relação do real". Não se trata, portanto, nem de voltar para dentro da caverna e estudar representações ou experiências múltiplas decorrentes da refração do Uno, nem de sair atrás do real desnudo e nem - como parece propor Fassin - de se expor, vez que outra, à luz do dia para tentar vislumbrar os fundamentos políticos e morais que constituiriam a "condição de possibilidade" dos gestos particulares observados pelo antropólogo (FASSIN, 2009, p. 205). A crítica, em tais circunstâncias, consiste em afirmar aquilo que, nas singularidades observadas, tensiona o estado de coisas que elas próprias atualizam singularmente. Para fins de contraste, poderíamos dizer que, nesta perspectiva, a crítica não passa necessariamente pela demonstração das condições de possibilidade de um determinado fenômeno e pela subsequente afirmação formal/moral de que as coisas poderiam ser diferentes do que são. Ao contrário, criticar é reivindicar uma subjetivação singular que torna efetivas as objetividades, inserindo-as num campo de possíveis que - com perdão da redundância - é o único realmente possível. Seguindo Lazarus, seria correto dizer que é muito difícil extrair possibilidades da mera apresentação - diacrônica ou sincrônica - desta ou daquela conjuntura. Para falar do que realmente pode vir a ser é preciso acompanhar um curso de pensamento/ação singular que prescreve o possível no elemento do dado.

Lazarus está nos convidando a começar a pesquisa social diretamente no campo aberto pela subjetivação de uma conjuntura e a permanecer ali até o final. Este campo se chama "situação". Um possível é, então, situação da conjuntura. A conjuntura, no sentido inverso, seria o estado da situação. Pode-se escolher entre pensar a partir do estado da situação ou a partir da situação da conjuntura. O primeiro caminho leva à ciência social descritiva, ao pensamento do que é, do que está e, poderíamos acrescentar, do que já foi. O segundo caminho nos leva a acompanhar o conhecimento prescritivo das pessoas e, portanto, o "possível" nele contido. Um dos caminhos, esclarece Lazarus,

propõe apreender o agora tendo em vista o estando (l'étant) e o outro sustenta que, no seu espaço de intelectualidade próprio, o que dá acesso ao "agora existente" (il y a maintenant) se elucida abordando o agora como conjunção de possíveis. O possível é, então, o que caracteriza a situação, o que assenta sua intelectualidade. O conhecimento de uma situação, para as pessoas, se apreende pela identificação dos seus possíveis. O possível não é da ordem do porvir, ele é da ordem do que há (de ce qu'il y a)" (LAZARUS, 2001, p. 395).

A detecção de possíveis, ou seja, de prescrições que caracterizam a abertura de uma situação tanto no pensamento como na prática não garante nenhuma utilidade social à pesquisa antropológica. Só "uma política" poderia oferecer tal garantia. Explico: a crítica imanente das "conjunturas" através do acompanhamento empírico das "situações" consiste, simplesmente, em enunciar um possível, nada mais. A respeito, Lazarus comenta que "emprender uma boa análise da situação certamente já é complexo, mas a organização da política é o que decidimos fazer" com as prescrições que encontramos no mundo (LAZARUS, 
2009, p. 216). "As prescrições são os lugares de atribuição do que é necessário fazer se queremos praticar uma política em interioridade" (Idem), isto é, uma política que não esteja baseada numa intelectualidade secundária, mas sim no movimento - ou relação - do real aberto pela singularidade do pensamento das pessoas.

O texto antropológico pode inaugurar "uma política"? Não necessariamente. A escrita antropológica pode, talvez, vir a participar de um agenciamento politizador que incida eficazmente sobre as relações de força concretas, mas nada está assegurado. A política é um assunto de coletividades e de alianças que garantem o devir do pensamento no campo social e a ampliação de sua capacidade prescritiva. A inclusão de um antropólogo neste tipo de processo depende, simultaneamente, de uma decisão ética e do azar das circunstâncias. Seja como for, a condição prévia para uma política interior ao real assenta na disponibilidade de enunciados críticos. Estes últimos devem ser entendidos, nos termos de Lazarus, já não como descrições, mas sim como prescrições situadas. O trabalho de campo está em condições de rastrear estas prescrições. Ele funciona como ferramenta de cartografia das conjunturas, expondo o etnógrafo a situações nas quais a imagem do mundo se desestabiliza, ou melhor para retornar a Lukács -, se dissolve prenunciando o novo.

Em minha pesquisa sobre dinâmicas de trabalho, deslocamento e indocumentação na fronteira brasileiro-uruguaia eu empreendi sucessivos exercícios cartográficos que me ajudaram a conceber certas prescrições imanentes às experiências de circulação transfronteiriça de algumas famílias de classe trabalhadora. Dentre os casos abordados na pesquisa em questão, selecionei aquele que considero o mais significativo para um exercício de demonstração do método esboçado no presente tópico. Este caso é relevante porque nos deixa antever como as prescrições dos sujeitos a respeito do que suas vidas poderiam ser se materializam, desde já, em espaços intersticiais de liberdade sem esgotar neles o campo de possíveis inaugurado pelo pensamento. O desafio assumido nas próximas páginas não é o de relançar o "trabalho indefinido da liberdade", mas sim o de definir as condições que a liberdade postula para existir, mesmo quando ela ainda não pode fazê-lo exatamente nos seus próprios termos.

\section{JORGE, SUSANA E SEUS FILHOS}

Antes de mudar-se para o povoado fronteiriço de Aceguá, onde o conheci, Jorge morava na cidade uruguaia de Artigas, limítrofe com Quaraí, no Estado do Rio Grande do Sul. Lá os amigos o haviam apelidado de golondrina (andorinha), porque trabalhava Brasil adentro no inverno e regressava à fronteira no verão para incorporar-se às frentes de trabalho mobilizadas pela atividade agrícola. Lembro-me que numa das visitas que fiz a sua casa, levei comigo uma cartolina branca e perguntei se poderia desenhar o mapa dos lugares 
por onde havia estado nas suas épocas de golondrina. Em poucos minutos começou a emergir do papel um circuito ovalado e contínuo, pontilhado de nomes de cidades, algumas delas uruguaias, a maioria sul-riograndenses: Montevidéu, Río Branco, Pelotas, Porto Alegre, Canoas, Novo Hamburgo, Dois Irmãos, Soledade, Mariante, Estrela, Lajeado, Carazinho, Caxias do Sul. Naquela oportunidade, meu interlocutor comentou que sua itinerância só veio a ser interrompida quando, num dos retornos estivais a Artigas, conheceu a atual esposa, Susana, também uruguaia. Diante dos planos de casamento nutridos por ambos, começar a trabalhar na coleta de resíduos recicláveis foi a alternativa encontrada por Jorge para sedentarizar-se. No entanto, o fechamento repentino do depósito de lixo onde trabalhava em Artigas acabou impondo novamente a necessidade do deslocamento, desta vez com a família.

Quando os conheci, já instalados em Aceguá, Jorge, a esposa e os três filhos se mantinham, basicamente, com o dinheiro da venda de materiais recicláveis e com as doações que Susana recebe quando percorre as escassas ruas da localidade em busca de ajuda financeira ou comida. Todos os meses também chegava uma cesta básica da Prefeitura de Aceguá, cujo sortimento vinha minguando sensivelmente nos últimos tempos. Menos frequentes eram as trocas de alimentos entre vizinhos, que se inserem num sistema de prestações assentado em vínculos de compadrio e afinidades religiosas bastante comum nas periferias de Aceguá. A respeito da coleta de resíduos, é importante observar que se trata de uma ocupação instável, porque como a maioria dos depósitos de lixo espalhados ao longo da linha de fronteira são irregulares, eles acabam interditados, cedo ou tarde, pelas autoridades sanitárias brasileiras ou uruguaias, segundo corresponda.

Imerso num contexto de grandes privações materiais, uma alternativa vislumbrada pelo casal para incrementar suas fontes de renda foi inscrever-se no programa Bolsa Família, do Governo Federal brasileiro. Entretanto, seu registro no Cadastro Único para Programas Sociais do Governo foi obstruído porque eles não possuíam documentos nacionais - ainda que os três filhos pequenos sim os possuíssem. Aqui, o condicionamento da atribuição de benefícios monetários à posse de documentos nacionais de identificação demonstra suas enormes limitações e desmorona num colapso paradoxal ao invisibilizar crianças brasileiras a partir da estrangeirização dos seus pais uruguaios. Esta situação de exclusão via indocumentação confrontou diretamente as expectativas do casal visto que, para ambos os cônjuges, o fato de estarem residindo no Brasil e terem filhos brasileiros justificaria, por si só, seu reconhecimento como caudatários da ajuda econômica do governo. Se nessas regiões fronteiriças as desvantagens de classe, justapostas à indocumentação, terminam convertendo os processos de margem em algo iminente, enfrentá-los torna-se um imperativo cotidiano que canaliza prescrições singulares sobre o significado da cidadania e a abrangência dos direitos. 
A implantação, em meados de 2011, do Escritório Binacional de Assistência Cidadã do Ministerio de Desarrollo Social uruguaio (MIDES) na fronteira de Aceguá foi uma ferramenta central para que Susana conseguisse levar adiante um percurso alternativo de cidadanização dos filhos. Isto porque referido órgão público estava autorizado a credenciar pessoas nos planos de distribuição de renda do Estado, facilitando o acesso à documentação nacional para indivíduos diagnosticados "em situação de vulnerabilidade social" ${ }^{6}$. Sendo de comum conhecimento entre os uruguaios que o MIDES é responsável pela promoção de programas sociais, Susana achou plausível consultar o Escritório Binacional sobre a possibilidade de receber algum apoio para suas crianças. Reparemos, aqui, que na noção de pertencimento nacional operada por minha interlocutora a questão da presença territorial não investia maior importância: sendo uruguaia ela acreditava poder dispor, independente de onde estivesse morando, de certa quantidade de recursos correspondente às suas urgências econômicas atuais. É interessante notar que esta concepção do "direito a ter direitos" dissociada da exigência de presença física em território nacional não é totalmente alheia à própria normativa uruguaia, pelo menos no que tange ao sistema de previdência social. Desde 1998, a lei nº 16.929 reconhece o direito a pensões de velhice e invalidez aos cidadãos nacionais residentes no Brasil ou na Argentina estabelecidos a uma distância não maior de cinco quilômetros do limite fronteiriço com o Uruguai. As coisas, contudo, são diferentes no caso dos programas de transferência de renda, cuja concessão está condicionada à presença territorial dos administradores do benefício e à inclusão dos seus filhos nas redes nacionais de saúde e educação.

Detenhamo-nos sobre este ponto para tornar mais evidente a lógica de funcionamento das Asignaciones Familiares uruguaias e do Programa Bolsa Família brasileiro. Ambos os programas sociais exigem dos seus beneficiários que fixem residência, obtenham documentos e matriculem os filhos nas escolas e creches do "lado certo" da divisa política, ou seja, nas respectivas jurisdições territoriais dos Estados que os promovem. Em sua página oficial, o MIDES informa que as Asignaciones Familiares buscam "complementar los ingresos familiares del hogar en situación de vulnerabilidad socioeconómica con menores a cargo. Se exige como contraprestación (...) la permanencia de los menores en el sistema educativo y la realización de controles de salud"7. Por sua vez, o Ministério de Desenvolvimento Social e Combate à Fome (MDS) afirma que o Programa Bolsa Família

está baseado na garantia de renda, inclusão produtiva e no acesso aos serviços

\footnotetext{
${ }^{6} \mathrm{Na}$ introdução eu mencionei que o acesso a documentação é relativamente restrito e caro nos pequenos povoados fronteiriços. Os Escritórios Binacionais do MIDES mitigaram temporariamente esta situação enquanto estiveram em funcionamento, entre 2011 e 2012, nas localidades de Aceguá, Rivera e Chuy.

Disponível em: http://www.mides.gub.uy/innovaportal/v/14546/3/innova.front/asignaciones familiares . Acesso em: maio de 2017.
} 
públicos (...) A transferência de renda promove o alívio imediato da pobreza. As condicionalidades reforçam o acesso a direitos sociais básicos nas áreas de educação, saúde e assistência social. Já as ações e programas complementares objetivam o desenvolvimento das famílias, de modo que os beneficiários consigam superar a situação de vulnerabilidade ${ }^{8}$.

Estes objetivos nos falam do desejo dos governos de regular as práticas sociais dos cidadãos de modo a garantir sua inserção social produtiva, ou seja, sua conversão em indivíduos socialmente úteis, melhorados física e intelectualmente através de relações sistemáticas com determinadas instituições públicas. Enquanto programas assistenciais estatais não-contributivos, tanto o Bolsa Família como as Asignaciones Familiares têm abrangência territorial delimitada e visam uma população específica: os cidadãos nacionais ou estrangeiros em situação migratória regular residentes no interior das fronteiras do Estado.

Circunscrever o uso dos benefícios apenas aos nacionais ou estrangeiros documentados é uma pretensão de assujeitamento que procura delimitar certo campo ideal de relações entre pessoas e coisas, entre os cidadãos e as instituições/recursos que thes correspondem. No entanto, como vimos, esse recorte ideal da população é posto constantemente em xeque devido a uma aporia impossivel de ser superada nos limites da razão de Estado. Poderíamos sintetizá-la da seguinte maneira: a negação de benefícios sociais aos estrangeiros termina, em muitos casos, afetando todos os nacionais que eventualmente se encontrem sob sua responsabilidade e deles dependam economicamente. Levando em conta que a indocumentação associa-se, frequentemente, à experiência de classe dos grupos subordinados fronteiriços, somos obrigados a concluir que as aporias da razão de Estado atingem proporções ainda mais dramáticas quando se entrelaçam com as políticas dirigidas às "pessoas em situação de vulnerabilidade", já que fazem com que estas mesmas políticas, em vez de mitigarem os efeitos de exclusão, terminem por reiterá-los. Mas se os objetivos estratégicos da pretensão de assujeitamento são colapsados pela própria lógica que os orienta, meu trabalho de campo permite demonstrar que, em sua práxis binacional cotidiana, as pessoas têm o poder de negar a negação de direitos e prescrever novos marcos para o exercício da cidadania. Vejamos como.

A respeito de Susana e Jorge, eu vinha dizendo que, uma vez impedidos de acessar o Programa Bolsa Família, eles procuraram o serviço fronteiriço do MIDES para consultar sobre a possibilidade de se inscreverem em programas sociais do governo uruguaio. Lá, informaram-nos de que suas crianças, por serem filhas de uruguaios natos, tinham direito a serem investidas da cidadania uruguaia. Por esta via, estariam autorizadas a receber as Asignaciones Familiares, mas apenas com a condição de que seus pais residissem no Uruguai e elas frequentassem os serviços públicos deste país. Como procederam, então, Jorge e

\footnotetext{
${ }^{8}$ Disponível em: http://www.mds.gov.br/bolsafamilia . Acesso em: novembro de 2012.
} 
Susana para fazer valer sua demanda por recursos? Em primeiro lugar, eles cumpriram com todos os trâmites de documentação das crianças, os quais transcorreram através do Escritório do MIDES sem nenhum custo e culminaram com a atribuição das carteiras de identidade. Em segundo lugar, eles tomaram emprestado o endereço de alguns conhecidos que residiam no Uruguai. Por fim, o casal matriculou seus filhos em instituições de ensino uruguaias e, utilizando o endereço emprestado, efetivou seu cadastro exitoso no programa de Asignaciones Familiares através do Ministerio de Desarrollo Social.

Os procedimentos enumerados nas últimas linhas do parágrafo anterior podem, sem dúvidas, ser interpretados como "táticas" - no sentido que thes atribui Michel de Certeau (2008 [1980]) - pelas quais os dominados tomam em suas mãos, parcial e transitoriamente, as regras do jogo social. Diferentes das "estratégias", que competiriam às instituições poderosas, capazes de promover seus objetivos sistematicamente "cincunscrevendo um próprio no mundo enfeitiçado pelos poderes invisíveis do Outro" (DE CERTEAU, 2008, p. 99), as táticas seriam muito mais heterogêneas, instáveis, não cumulativas. Reproduzir-se-iam em todos os lugares, no golpe a golpe da vida cotidiana, vampirizando as tecnologias de poder. Ao fim e ao cabo, as táticas são isto: uma potencialidade enquistada no lugar do "outro" do poder. Sem descartar esta perspectiva, sugiro que é possível ampliá-la, de forma a enfatizar com mais acuidade as prescrições inesperadas que cintilam na irrupção localizada das táticas quando os sujeitos são convidados a narrá-las e a ponderar sobre seus sentidos.

Minha proposta, então, é interpretar o manejo que Susana e Jorge fizeram das tecnologias estatais de governo de populações como uma postura tática de "cumplicidade subversiva" com o sistema. Esta noção, proposta por Santiago Castro-Gómez e Ramón Grosfoguel (2007), procura dar conta de operações de resistência semiótica às formas hegemônicas de conhecimento e de exercício do poder a partir de intelectualidades outras, forjadas numa práxis que é exterior ao pensamento de Estado e que reflete, portanto, concepções singulares a respeito do limite dos territórios e da abrangência dos direitos. Eduardo Restrepo e Axel Rojas entendem que essa "cumplicidade" das formas intersticiais de saber e fazer é subversiva porque "não implica nem que os conteúdos, nem que as modalidades destes conhecimentos se limitem a reproduzir as configurações de poder que os constituem" (RESTREPO; ROJAS, 2010, p. 197).

Ao documentarem seus filhos e matriculá-los em escolas uruguaias, Susana e Jorge seguiram o script nacionalista do programa social que desejavam solicitar. Contudo, ao continuarem residindo no Brasil, eles subverteram o viés territorial das Asignaciones Familiares, impugnando parcialmente a pretensão de assujeitamento que pretendia condicionar a concessão de recursos estatais à presença fixa dos sujeitos nos limites de uma dada jurisdição nacional. Fazendo isso, eles não só contra-arrestaram a invisibilidade dos filhos no Brasil, como também estenderam de facto, na medida das suas necessidades e 
urgências, o próprio horizonte de vigência da cidadania uruguaia, ajustando-a às contingências de uma vida binacional. Neste sentido, em relação ao Estado uruguaio, a prescrição de Jorge e Susana pode ser sintetizada assim: ninguém deve ser abandonado; todos os nacionais contam, mesmo residindo do outro lado da fronteira.

Jorge, no entanto, continua insatisfeito porque ao longo de todos esses movimentos táticos ele considera que algo importante foi perdido: a possibilidade de escolha dos seus filhos. "Eu gostaria - refletia Jorge - que eles mesmos decid[issem] a vida deles sem ficar dependendo dos dois países". Depender de dois países, no final das contas, não é o melhor dos mundos. Significa estar permanentemente defrontado com a necessidade de ir buscar em um lado aquilo que o outro se nega a oferecer; implica, também, estar pendente das "Falhas de vigilância" dos governos para alcançar avanços táticos cotidianos que permitam seguir equilibrando possibilidades sempre parciais de acesso à cidadania. Ainda assim, depender de dois países pode ser melhor do que depender apenas de um, como acontecia com outros interlocutores de minha pesquisa estabelecidos em localidades mais distantes da divisa política.

Por residirem nas proximidades da fronteira, Jorge e Susana conseguem enfrentar com maior desenvoltura os impasses da razão de Estado, não ficando completamente à deriva entre a norma e o estado de exceção instaurados por um único país. É como se ao seu alcance sempre houvesse um segundo tabuleiro de jogo que está negado a outras pessoas em decorrência da distância física que as separa da fronteira. Este segundo tabuleiro - que conforme a situação chama-se Brasil ou Uruguai - permite a abertura de uma instância alternativa de negociação da cidadania; uma última instância cuja disponibilidade posterga, pelo menos transitoriamente, a instauração de um processo absoluto de exclusão. Apesar de este processo ter sido evitado graças à cumplicidade subversiva com o Estado uruguaio, a prescrição que Jorge endereça ao Estado brasileiro continua latente. É possível depreendê-la da reflexão transcrita mais acima, na qual meu interlocutor lamenta que os filhos tenham perdido sua capacidade de escolha. Trata-se de uma prescrição que afirma a prerrogativa de reconhecimento das crianças independentemente da nacionalidade ou do estatuto migratório de seus pais.

\section{OBSERVAÇÕES FINAIS: PRESCRIÇÃO, CRÍTICA E POLÍTICA}

Da divisão radical entre nacionais e estrangeiros decorrem múltiplos percalços que confrontam quem decide se deslocar através da fronteira brasileiro-uruguaia. Pessoas como Jorge, Susana e seus filhos acabam expostas ao abandono jurídico quando os estados nacionais condicionam a distribuição de certos recursos públicos à posse de documentos que comprovem cidadania nacional ou situação migratória regular. Sem documentos, meus 
interlocutores correm o risco constante de ficar invisibilizados. Tornam-se, do ponto de vista da lógica estatal, uma "pobreza exótica" e insolúvel, para utilizar a sugestiva expressão de Abdelmalek Sayad (2001). Apesar das políticas comuns de reconhecimento dos direitos cidadãos no Mercosul, os circuitos de deslocamento transfronteiriço continuam produzindo, por razões que foram discutidas ao longo do texto, sujeitos às margens do Estado. Trata-se de sujeitos inscritos em certo diagrama de poder no qual "estar" num território nem sempre significa "existir" para o Estado que o governa.

A "inexistencialização" jurídica dos sujeitos deriva de encontros institucionais malogrados que thes impedem de acessar os recursos econômicos controlados pelos estados-nação que administram os territórios onde vivem. Contudo, as tentativas de negação pragmática das lógicas de exclusão vigentes transmutam os imperativos da necessidade econômica numa ética imanente da inclusão e do merecimento que nos autoriza a afirmar que as coisas, objetivamente, podem ser diferentes do que são. Mesmo inscritos numa zona de exclusão legal, meus interlocutores conseguiram gestionar ao seu modo os benefícios sociais dos quais se julgavam merecedores. Procedendo assim eles exerceram, mesmo que de forma limitada, direitos que ainda não têm. Iniciativas desta natureza constituem uma crítica corporizada das limitações inerentes ao conceito nacionalista de cidadania, ao passo que também dão testemunho de outras formas possíveis de viver a estatalidade e de subverter o viés territorial do "direito a ter direitos".

No momento em que a lógica dualista do pensamento de Estado se atualiza sobre os corpos através de práticas institucionais de escrutínio, tornam-se evidentes tanto as suas condições de possibilidade como as suas condições de impossibilidade. É então que podemos fazer um balanço localizado do presente e acompanhar os devires autônomos que anunciam outro estado de coisas possível. A singularidade configurada pelas trajetórias de Jorge e Susana nos diz uma verdade paradoxal sobre o funcionamento do poder soberano nas fronteiras do Mercosul. Esta verdade é paradoxal porque contradiz criticamente o postulado nacionalista segundo o qual seria possível discernir entre estrangeiros e nacionais no momento de distribuir racionalmente os recursos monopolizados pelo Estado. Na fronteira brasileiro-uruguaia, nacionais e estrangeiros estão frequentemente entrelaçados por vínculos de potestade e dependência ilegíveis aos olhos da normativa vigente. Na prática, isto significa que perante determinados grupos e não importando a nacionalidade dos seus membros o Estado atua a priori como operador de uma exclusão generalizada. O poder soberano nega a forma de vida transfronteiriça e binacional das classes populares indocumentadas. A posteriori, tal negação poderá ser negada taticamente com chances variáveis de êxito. Os infortúnios dos meus interlocutores revelam, portanto, o sentido concreto assumido pelo escrutínio estatal nos territórios onde desenvolvi trabalho de campo. Quando digo "sentido concreto", não estou afirmando que a exclusão generalizada 
via indocumentação é um objetivo premeditado das instituições burocráticas, mas sim que constitui sua expressão real num dado território.

No primeiro tópico, em diálogo com Sylvain Lazarus, eu sugeria que a crítica imanente consiste em afirmar aquilo que, na singularidade observada, tensiona o estado de coisas que ela própria reproduz "singularmente". O desafio básico que este procedimento crítico nos coloca consiste em passar da descrição do "estado da situação" para a enunciação da "situação da conjuntura" na esteira do pensamento das pessoas e de seus eventuais desdobramentos táticos. A prospecção dos efeitos reais de poder revelados pela interação entre pessoas e instituições públicas precisa ser sempre complementada com a sinalização de alguns critérios possíveis de transformação da situação abordada. Estes critérios, que poderíamos denominar "condições de impossibilidade" da realidade atual, tornam-se visíveis quando as pessoas encontram uma forma de obter aquilo que necessitam mesmo não estando autorizadas a fazê-lo. A resolução tática das necessidades materiais objetivas se converte, então, em ocasião para a afirmação de uma liberdade possível, mas não garantida.

A liberdade se afirma "taticamente" enquanto os possíveis que ela comporta ainda não estão chancelados por um poder que assegure sua realização incondicional. Exercendo a liberdade tática, sujeitos como Jorge e Susana se eximem do estado de exceção decorrente de uma eventual realização absoluta dos efeitos da exclusão via indocumentação. Contudo, sua capacidade radical de escolha permanece em suspenso, sob a forma de uma independência desejada, mas fugidia, frente ao arbítrio de dois países que parecem estar sempre dispostos a desconhecer obstinadamente as modalidades concretas da presença territorial das pessoas. Só poderia haver uma capacidade efetiva de escolha por meio da estabilização daquilo que as táticas nos permitem vislumbrar com tenuidade, a saber: a possibilidade de uma articulação imediata entre estar e ser, independente do fator nacionalidade.

Da mesma forma que as táticas e suas prescrições imanentes, a crítica meramente textual - é o caso deste artigo - permanecerá circunscrita a um frágil "não lugar" enquanto estiver dissociada da enunciação política coletiva dos possíveis que ela reverbera. Mas, ainda assim - e novamente em analogia com as táticas -, será um pouco mais que nada; será o sonho materialista do possível, a apresentação de um agonismo concreto que ainda não é política. Qual seria, então, a vantagem - se é que faz sentido falar nestes termos - do procedimento crítico exposto nesta intervenção? Basicamente, uma vantagem política potencial que consiste em compartilhar a modesta notícia de que existe gente prescrevendo possíveis, de que a conjuntura está aberta e as pessoas a vivem como tal. Trata-se, por conseguinte, de uma abertura real e vivida; simplória em sua atualização e, ao mesmo tempo, radical em suas prescrições. É nesta abertura - mais do que num trabalho da liberdade indefinido e sem sujeito - que "uma política" poderia, quem sabe, vir a ser. 


\section{REFERÊNCIAS}

CASTRO-GÓMEZ, Santiago; GROSFOGUEL, Ramón. Prólogo. Giro decolonial, teoría crítica y pensamiento heterárquico. In: CASTRO-GÓMEZ, S., GROSFOGUEL, R (orgs.). El giro decolonial. Reflexiones para una diversidad epistémica más allá del capitalismo global. Bogotá: Iesco-Pensar-Siglo del Hombre Editores, 2007. p. 9-23.

DE CERTEAU, Michel. A invenção do cotidiano. Petrópolis: Vozes, 2008.

FASSIN, Didier. La seducción del humanitarismo. Buenos Aires: 2014. Revista Ñ Diario Clarín. Buenos Aires, 10 dez. 2014. Entrevista concedida a M. Dimapoulos. Disponível em: http://www.clarin.com/ideas/didier-fassin-seduccion-humanitarismo 0 HyjNTYDqwmg.html. Acesso em: novembro de 2016.

FASSIN, Didier. Introduction: Towards a Critical Moral Anthropology. In: FASSIN, D. (org.). A Companion to Moral Anthropology. Malden: Wiley-Blackwell, 2012. p. 1-23.

FASSIN, Didier. A contribution to the critique of moral reason. Anthropological Theory, v. 11, n. 4, p. 481-491, 2011a.

FASSIN, Didier. Humanitarian Reason: A Moral History of the Present. Berkeley: University of California Press, $2011 \mathrm{~b}$.

FASSIN, Didier. Une science sociale critique peut-elle être utile? Tracés. Revue de Sciences Humaines, n. 9, p.199-211, 2009.

FASSIN, Didier; D'HALLUIN, Estelle. The truth from the body: Medical certificates as ultimate evidence for asylum seekers. American Anthropologist, v.107, n. 4, p.597-608, 2005.

FASSIN, Didier. Gobernar por los cuerpos, políticas de reconocimiento hacia los pobres y los inmigrantes en Francia. Cuadernos de Antropología Social, n. 17, p. 49-78, 2003.

FASSIN, Didier. Quand le corps fait loi. La raison humanitaire dans les procédures de régularisation des étrangers. Sciences sociales et santé, v. 19, n. 4, p. 5-34, 2001.

GUILHOT, Nicolas. The Anthropologist as Witness: Humanitarianism between Ethnography and Critique. Humanity: An International Journal of Human Rights, Humanitarism and Development, v. 3, n. 1, p. 81-101, 2012.

JIMENO, Myriam. La vocación crítica de la antropología latinoamericana. Maguaré, n. 18, p. 33-58, 2004.

LAZARUS, Sylvain. Anthropologie du nom. Paris: Editions du Seuil, 1996.

LAZARUS, Sylvain. Anthropologie ouvrière et enquête d'usine: état des lieux et problématique. Ethnologie française, v. 31, n. 3, p. 389-400, 2001.

LAZARUS, Sylvain. Sur une nouvelle politique contemporaine et sur la philosophie de la politique de Louis Althusser lecteur de Lénine. Socio-anthropologie, v. 23-24, p. 211-236, 2009. 
LUKÁCS, György. Para uma ontologia do ser social I. São Paulo: Boitempo, [1984] 2012.

LUKÁCS, György. Historia y Conciencia de Clase. Buenos Aires: Razón y Revolución, [1922] 2013.

MORAES, Alex. Negociando às/as margens: experiências de trabalho, deslocamento, indocumentação e acesso aos serviços do Estado na fronteira brasileiro-uruguaia. Dissertação - Antropologia Social, Universidade Federal do Rio Grande do Sul, Porto Alegre, 209 pp., 2013. Disponível em: http://www.lume.ufrgs.br/handle/10183/76238. Acesso em: janeiro de 2017.

MORAES, Alex. Biocapital, indocumentação e experiência de classe na fronteira uruguaio-brasileira, Pacarina del Sur en línea, v. $5, n$. 18, $s / n, 2014$. Disponível em: www.pacarinadelsur.comindex.php?option=com content\&view=article\&id=882\&catid=14. Acesso em: janeiro de 2017.

PEIRANO, Mariza. The anthropology of anthropology. The Brazilian case. PhD. dissertation, Department of Anthropology, Harvard University. 180 pp., 1981.

RESTREPO, Eduardo; ROJAS, Axel. Inflexión decolonial - fuentes, conceptos y cuestionamientos. Popayán: Samava, 2010

SAYAD, Abdelmalek. Uma pobreza 'exótica': a imigração argelina na França. Revista Brasileira de Ciências Sociais, n.17, p.84-107, 1991.

WALZER, Michael. La critique sociale au XXe siècle. Solitude et solidarité, Paris: Métailié, 1996. 